Article

\title{
$N$-Alkylisatin-Loaded Liposomes Target the Urokinase Plasminogen Activator System in Breast Cancer
}

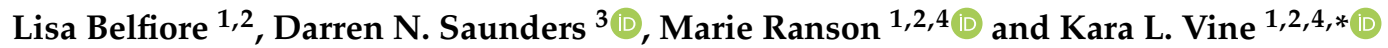 \\ 1 Illawarra Health and Medical Research Institute, Wollongong, NSW 2522, Australia; \\ lisa.belfiore@inventia.life (L.B.); mranson@uow.edu.au (M.R.) \\ 2 School of Chemistry and Molecular Bioscience, Faculty of Science Medicine and Health, \\ University of Wollongong, Wollongong, NSW 2522, Australia \\ 3 School of Medical Sciences, University of New South Wales, Sydney, NSW 2052, Australia; \\ d.saunders@unsw.edu.au \\ 4 CONCERT-Translational Cancer Research Centre, Sydney, NSW, Australia \\ * Correspondence: kara@uow.edu.au
}

Received: 26 May 2020; Accepted: 3 July 2020; Published: 7 July 2020

check for updates

\begin{abstract}
The urokinase plasminogen activator and its receptor (uPA/uPAR) are biomarkers for metastasis, especially in triple-negative breast cancer. We prepared anti-mitotic $N$-alkylisatin (N-AI)-loaded liposomes functionalized with the uPA/uPAR targeting ligand, plasminogen activator inhibitor type 2 (PAI-2/SerpinB2), and assessed liposome uptake in vitro and in vivo. Receptor-dependent uptake of PAI-2-functionalized liposomes was significantly higher in the uPA/uPAR overexpressing MDA-MB-231 breast cancer cell line relative to the low uPAR/uPAR expressing MCF-7 breast cancer cell line. Furthermore, N-AI cytotoxicity was enhanced in a receptor-dependent manner. In vivo, PAI-2 N-AI liposomes had a plasma half-life of $5.82 \mathrm{~h}$ and showed an increased accumulation at the primary tumor site in an orthotopic MDA-MB-231 $\mathrm{BALB} / \mathrm{c}-$ Fox1nu/Ausb xenograft mouse model, relative to the non-functionalized liposomes, up to $6 \mathrm{~h}$ post-injection. These findings support the further development of N-AI-loaded PAI-2-functionalized liposomes for uPA/uPAR-positive breast cancer, especially against triple-negative breast cancer, for which the prognosis is poor and treatment is limited.
\end{abstract}

Keywords: $N$-alkylisatin; liposome; urokinase plasminogen activator; PAI-2; SerpinB2; breast cancer

\section{Introduction}

Breast cancer is the most common invasive cancer in women worldwide and remains a leading cause of cancer-related morbidity and mortality [1]. While overall survival has improved steadily over the last several decades, breast cancer still accounts for almost half a million deaths each year [2]. Numerous studies and clinical evidence indicate that the urokinase plasminogen activator system (uPAS) play a key role in breast cancer metastasis [3,4]. In this system uPA, secreted as a zymogen, is activated upon binding to its specific cell surface receptor uPAR. Once activated, uPA catalyzes the activation of co-localized plasminogen to plasmin, which in turn directly degrades the components of the extracellular matrix (ECM), promoting further degradation and tissue remodeling, by activating pro-metalloproteinases and activating latent growth factors from the ECM [5]. Localization of the uPAS at the invasive front of tumors thus facilitates cell migration and invasion. In breast cancer, progression-free survival is inversely correlated with uPA and UPAR expression [6,7]. Patients with high uPA mRNA levels are more likely to suffer from metastatic disease [8], and overexpression of uPAR by tumor cells or stromal cells is associated with a poor prognosis for metastatic breast cancer [9]. 
Amplification and overexpression of $\mathrm{UPA}$ and $\mathrm{UPAR}$ are thus recognized biomarkers of metastasis and are indicative of an overall poor patient prognosis for breast and several other cancer types $[6,7,10,11]$.

In the triple-negative breast cancer (TNBC) subtype, uPAR was also shown to increase the malignant potential [12] and was identified as a possible novel target for treatment $[13,14]$. As this subtype lacks the three main breast cancer molecular biomarkers (estrogen receptor (ER), progesterone receptor (PR), and human epidermal growth factor receptor 2 (HER2)), there are no targeted therapy options for TNBC, and the use of conventional chemotherapies remains the standard of care. In addition, TNBC is a markedly heterogeneous subtype that can make treatment problematic. The prognosis of TNBC is generally poor, with high rates of disease recurrence and relapse. The progression-free survival and overall survival rates of TNBC patients are significantly shorter than those of non-TNBC patients [15].

Given the role of uPAS in the promotion of metastasis, targeting uPA/uPAR is a promising therapeutic strategy for TNBC [16,17]. uPA is efficiently and specifically inhibited by the serpin plasminogen activator inhibitor-2 (PAI-2/SerpinB2), forming a covalent complex with uPA/uPAR, which is rapidly internalized via endocytosis receptors [18,19]. Previous work by our group showed that PAI-2 could be used as a targeting ligand for the intracellular delivery of covalently attached cytotoxins to uPAR-positive tumor cells [5,20,21]. Specifically, PAI-2 was conjugated to an $N$-alkylisatin (N-AI)-based cytotoxin, a potent microtubule destabilizing agent [22], which could evade P-glycoprotein (P-gp)-mediated efflux in multi-drug resistant cancer cell lines $[23,24]$. The N-AI-PAI-2 conjugate was efficacious in vivo, reducing MDA-MB-231 tumor growth at 1/20th of the dose of free N-AI [25]. Given the potency and previous validation of $N$-AI as a cytotoxin for use in anticancer applications, $N$-AI is a promising candidate for further development in drug delivery research. As a hydrophobic molecule, $N$-AI has a low aqueous solubility that limits the amount of drug that can be administered intravenously [26]. However, $N-\mathrm{AI}$ is amenable to encapsulation within liposomes, in order to improve solubility and physicochemical stability.

Liposomes emerged as a useful delivery system for the transport of drugs and other molecules to solid tumors. Their unique structure allows for the encapsulation of hydrophobic or hydrophilic drugs in the lipid bilayer or aqueous core, respectively [27]. Encapsulated drugs can then be delivered to target cells for intracellular drug release and anti-tumor effect. The inclusion of hydrophilic polymers, most commonly PEG, at the outer surface of the liposome can increase the in vivo circulation time, by reducing recognition and clearance by the MPS [28]. For this reason, PEGylated liposomes were long considered a clinically useful nanoparticle for drug delivery applications. In addition to their versatile drug encapsulation capabilities, liposomes permit the active targeting of specific cell types via the conjugation of ligands to the liposome surface, for drug delivery to cells expressing the target surface receptor(s) of interest $[29,30]$. Following liposome extravasation into the tumor interstitial space, subsequent ligand-directed surface binding and internalization promotes liposome and drug entry into specific cell types. As targeted liposome formulations combine both passive and active drug delivery mechanisms, ligand-directed liposomes should show superior drug delivery, compared to non-ligand liposomes, depending on the tumor type [31].

Herein, we describe the preparation and characterization of novel N-AI-loaded liposomes surface-functionalized with PAI-2 as a ligand for targeting uPA/uPAR. We further evaluated the cellular targeting and in vivo biological properties of these liposomes, using relevant models of uPAR-positive TNBC breast cancer.

\section{Materials and Methods}

\subsection{Liposome Preparation and Characterization}

Liposomes were prepared using the thin-film hydration method [31] and were composed of $20 \mathrm{mM}$ soy PC (L- $\alpha$-phosphatidylcholine) and 0.6 mM mPEG2000-DSPE (1,2-distearoyl-sn-glycero3-phosphoethanolamine- $N$-[(polyethylene glycol)-2000]) (Avanti Polar Lipids, Alabaster, AL, USA), with the addition of either $5 \mathrm{mM}$ cholesterol (Sigma-Aldrich, St. Louis, MO, USA) to form empty 
liposomes, or $5 \mathrm{mM}$ 5,7-dibromo- $N$-( $p$-hydroxymethylbenzyl)isatin ( $N$-AI) (prepared in-house [23]) to form $\mathrm{N}$-AI-loaded liposomes. $\mathrm{N}$-AI encapsulation efficiency was determined by high-performance liquid chromatography (HPLC). Here, $N$-AI-loaded liposomes were mixed with water/acetonitrile $(60: 40 v / v)$ and centrifuged. The $N$-AI concentration was determined using an Atlantis T3 reverse-phase C18 analytical column (Waters, UK) and a Waters HPLC machine (Waters, MA, USA). Analysis was performed using an injected volume of $10 \mu \mathrm{L}$, with a gradient elution and monitored with a photodiode array at $435 \mathrm{~nm}$. Concentration was determined by interpolating from a standard curve after analysis of standards and samples using Empower Pro V2 software (Waters, UK).

Liposomes were surface-functionalized with plasminogen activator inhibitor type 2 (PAI-2), as described by our group previously [31]. Unbound PAI-2 was removed from liposomes by sizeexclusion chromatography (SEC), using Sepharose CL-4B (Sigma-Aldrich, MO, USA). Western blotting and fluorogenic uPA activity assays were used to detect and quantify PAI-2 conjugated to liposomes and the activity of PAI-2-functionalized liposomes [32]. For Western blotting, PAI-2 in SDS-PAGE gels (reducing conditions) were transferred to PVDF membranes using Bio-Rad transfer equipment (Bio-Rad Laboratories, Hercules, CA, USA) at $100 \mathrm{~V}$ for $1.5 \mathrm{~h}$. Membranes were rinsed in TBST (1× TBS buffer with $0.05 \% v / v$ Tween-20) and blocked using $10 \%$ skim milk in TBST for $1 \mathrm{~h}$ at RT. After the rinsing membranes were incubated with primary antibody (anti-SerpinB2; Abcam, Cambridge, UK) at 1:2000 dilution in $2 \%$ skim milk/TBST at $4{ }^{\circ} \mathrm{C}$ overnight. Membranes were washed with TBST four times (10 min each wash) and then incubated with secondary antibody (anti-rabbit-HRP; Abcam, Cambridge, UK) at 1:5000 dilution in 2\% skim milk/TBST for $2 \mathrm{~h}$ at RT. Membranes were then washed in TBST, three times, for $5 \mathrm{~min}$ and then in TBS (no Tween-20), three times, for $5 \mathrm{~min}$. Membranes were developed using ECL peroxidase reaction (Pierce PicoWest ECL reagent; Thermo Fisher Scientific, Waltham, MA, USA), according to the manufacturer's instructions. Membranes were visualized using X-ray film, after developing and fixing (Bio-Rad Laboratories, CA, USA) or using a Gel Logic 2200 Digital Imager (Carestream Molecular Imaging, Woodbridge, CT, USA). Band intensities were quantified using ImageJ (National Institutes of Health, Bethesda, MD, USA).

\subsection{Cell Lines and $u P A$ and $u P A R$ Expression}

The human mammary epithelial invasive ductal carcinoma cell lines MCF-7 and MDA-MB-231 were purchased from the American Type Culture Collection (ATCC, Manassas, VA, USA). Cells were cultured in RPMI-1640 medium (Life Technologies, Carlsbad, CA, USA) containing $24 \mathrm{mM} \mathrm{NaHCO}$ and supplemented with $10 \%(v / v)$ heat-inactivated fetal bovine serum (FBS; Thermo Fisher Scientific, MA, USA). Cells were maintained in culture at $37^{\circ} \mathrm{C}$ in a $95 \%$ humidified atmosphere with $5 \% \mathrm{CO}_{2}$ in a HERAcell incubator (Kendro Laboratory Products, Germany). For passaging, the cells were harvested by treatment with $0.05 \%$ trypsin-EDTA (Life Technologies, CA, USA), followed by centrifugation at $300 \times g$ for $5 \mathrm{~min}$. For the experiments, the cells were harvested by treatment with PBS containing $5 \mathrm{mM}$ EDTA ( $\mathrm{pH}$ 7.4), followed by centrifugation at $300 \times \mathrm{g}$ for $5 \mathrm{~min}$. Viable cells were counted with a hemocytometer using the Trypan Blue (Sigma-Aldrich, MO, USA) exclusion method. Cell lines were routinely tested and confirmed to be negative for mycoplasma contamination (in-house testing conducted by the Illawarra Health and Medical Research Institute Technical Services Unit). Cell lines were confirmed to be negative for cross-contamination by short-tandem repeat (STR) sequencing (performed by the Garvan Institute of Medical Research, Darlinghurst, Australia).

Expression of uPA and uPAR on the surface of cells was determined by flow cytometry, as described in Supplementary Information.

\subsection{Assessment of Cellular Uptake and Localization of Liposomes}

MCF-7 and MDA-MB-231 cells were used to assess the cellular uptake of liposomes through flow cytometry and cellular localization by confocal microscopy. For flow cytometry, MCF-7 and MDA-MB-231 cells $\left(2 \times 10^{5}\right.$ cells/well $)$ were seeded into 12-well plates and allowed to attach for $24 \mathrm{~h}$ at $37^{\circ} \mathrm{C}$. Liposomes containing $1 \%(\mathrm{~mol} / \mathrm{mol})$ FITC-PEG 2000 -DSPE were added to wells at dilutions 
ranging from 1:20 to 1:5. At specified time intervals ranging between 15 and 60 min, the supernatant was removed, the cells were washed once with PBS and then harvested using PBS containing $5 \mathrm{mM}$ EDTA ( $\mathrm{pH} 7.4)$. The cells were then centrifuged (300 $\mathrm{g}$ for $5 \mathrm{~min}$ ) and washed three times with PBS, before being resuspended in $200 \mu \mathrm{L}$ PBS for analysis. The fluorescence intensity was determined by flow cytometry (LSR II flow cytometer; BD Biosciences, CA) (excitation $488 \mathrm{~nm}$, emission collected with 515/20 band-pass filter). FlowJo software (V10; Tree Star Inc., OR, USA) was used to evaluate the mean fluorescence intensity (MFI), to determine the cellular uptake of liposomes.

For confocal microscopy, cells (50,000 per well) were seeded into 8-well $\mu$-Slide chambered coverslips (ibidi, Germany) and incubated for $24 \mathrm{~h}$ at $37^{\circ} \mathrm{C}$. Cells were allowed to reach $80 \%$ confluence before the addition of liposomes. Liposomes containing $1 \%$ or $10 \%$ (mole $\%$ of liposome phospholipid) FITC-PEG 2000 -DSPE, or $0.625 \%$ (mole \% of liposome phospholipid) octadecyl rhodamine B chloride (R18; Invitrogen, Carlsbad, CA, USA) were added to cells at dilutions ranging from 1:5 to 1:10, and incubated for $30 \mathrm{~min}$ to $2 \mathrm{~h}$ at $37^{\circ} \mathrm{C}$. The supernatant was removed and the wells were rinsed three times with PBS, before LysoTracker Green DND-26 (excitation/emission 504/511 nm; Thermo Fisher Scientific, MA, USA) was added to each well (50 nM final concentration), immediately prior to imaging. Live imaging of cells in PBS was performed using a Leica TCS SP5 Confocal Microscope (Leica Microsystems, Wetzlar, Germany) and the images were acquired using a $63 \times$ oil immersion lens. Images were analyzed using the Leica Application Suite software (V10; Leica Microsystems, Germany).

\subsection{D multicellular Tumor Spheroid Cytotoxicity Assays}

MCF-7 or MDA-MB-231 cells were seeded into ultra-low attachment 96-well plates (Sigma-Aldrich, MO, USA), at a density ranging between 625 and 5000 cells per well and incubated at $37^{\circ} \mathrm{C}$ to promote spheroid formation. Liposomes were serially diluted in PBS and incubated with cells for up to $96 \mathrm{~h}$ (each concentration tested in triplicate).

\subsection{Pharmacokinetics and Biodistribution of N-AI PAI-2 Liposomes in Mice}

Female BALB/c-Fox1nu/Ausb nude immunocompromized mice (5 weeks old) (Australian BioResources, Moss Vale) were housed in isolator cages at the University of Wollongong animal facility. Mice were given food and water ad libitum and kept on a 12-h light/dark cycle for the duration of the experiment. Mice were allowed to acclimatize for 2 weeks before commencement of the experiment. All experiments were conducted in accordance with the 'NHMRC Australian Code for the Care and Use of Animals for Scientific Purposes', which requires 3R compliance (replacement, reduction, and refinement) at all stages of animal care and use, and the approval of the Animal Ethics Committee of the University of Wollongong (Australia) under protocol AE13/18. MDA-MB-231 cells (ATCC; mycoplasma negative and STR profiled) were resuspended in PBS (no Ca/Mg; pH 7.4; Sigma-Aldrich, MO, USA) and counted using Trypan blue (Sigma-Aldrich, MO, USA) and a hemocytometer. Insulin syringe needles (29-gauge; BD Biosciences, NJ, USA) were used to inject $50 \mu \mathrm{L}$ of cell suspension (containing $2 \times 10^{6}$ cells) into the upper left mammary fat pad. Mice were injected one cage at a time and the injection order of cages was randomized. Mice were monitored closely following the injection of cells, and the tumors were observed to form at approximately 3 weeks post-injection.

Tumors were $<100 \mathrm{~mm}^{3}$ upon commencement of liposome treatment. Mice were randomly allocated to treatment ( $\mathrm{N}$-AI liposome or N-AI PAI-2 liposome) and time-point (10 min, $3 \mathrm{~h}, 6 \mathrm{~h}$, $24 \mathrm{~h}, 48 \mathrm{~h}$ or $96 \mathrm{~h}$ ) groups ( 4 mice per cohort). Treatments (100 $\mu \mathrm{L} ; 4 \mu \mathrm{Ci} / \mathrm{mouse})$ were administered intravenously via a single lateral tail-vein injection. Mice that were deemed significantly $( \pm 10 \%)$ smaller or larger in weight than their cage mates had their dose volume adjusted proportionally, based on their weight, relative to the average of their cage mates. The ${ }^{3} \mathrm{H}-\mathrm{CHE}$ radioactivity (liposome) in the plasma, kidneys, liver, spleen, lungs, tumor and tail (for injection correction) was quantified using previously published methods [33]; further details are provided in Supplementary Information. 


\subsection{Toxicology of N-AI Liposomes in Mice}

The toxicology of $N$-AI liposomes was determined in female BALB/c mice via single or multiple lateral tail-vein injections. Details are described in Supplementary Information.

\subsection{Data Analysis}

All data analysis, including the generation of graphs and statistical tests, was performed using GraphPad Prism version 7 for Windows (GraphPad Software, CA, USA), unless stated otherwise. Data are presented as the mean \pm standard deviation (s.d.) or standard error of the mean (s.e.m.) as stated. Pairwise comparisons were made using Student's $t$-test and multiple comparisons were made using one-way ANOVA with Tukey's post-test.

\section{Results}

\subsection{Preparation and Characterization of Liposomes}

Modifications to our previously reported method [33] were used to prepare and characterize the PEGylated liposomes containing the potent microtubule-destabilizing agent 5,7-dibromo- $N$ ( $p$-hydroxymethylbenzyl)isatin ( $N$-AI; see Supplementary Information Figure S1 for chemical structure), surface functionalized \pm PAI-2. The particle diameter, polydispersity index (PDI), peak intensity, and zeta potential for all liposome preparations are summarized in Table 1.

Table 1. Characterization of empty and N-AI PEGylated liposomes. Empty (EMP) liposomes, $\mathrm{N}$-AI-loaded (N-AI) liposomes, empty PAI-2-functionalized (EMP PAI-2) liposomes, and N-AI-loaded PAI-2-functionalized (N-AI PAI-2) liposomes were prepared by the thin-film hydration method and analyzed by dynamic light scattering. Values are means \pm s.d. $(n=3)$.

\begin{tabular}{cccccc}
\hline Liposome & Diameter (nm) & $\begin{array}{c}\text { Polydispersity } \\
\text { Index }\end{array}$ & Peak Intensity \% & $\begin{array}{c}\text { Zeta Potential } \\
(\mathbf{m V})\end{array}$ & $\begin{array}{c}\text { Phospholipid } \\
\text { (mM) }\end{array}$ \\
\hline EMP & $137.6 \pm 5.6$ & $0.067 \pm 0.04$ & 100 & $-3.63 \pm 0.80$ & 16.44 \\
N-AI & $139.9 \pm 3.9$ & $0.093 \pm 0.02$ & 100 & $-3.64 \pm 0.59$ & 16.45 \\
EMP PAI-2 & $139.7 \pm 4.9$ & $0.109 \pm 0.02$ & 100 & $-4.05 \pm 0.53$ & 16.67 \\
N-AI PAI-2 & $141.1 \pm 5.0$ & $0.086 \pm 0.03$ & 100 & $-4.66 \pm 0.52$ & 16.62 \\
\hline
\end{tabular}

\# Percent of particles present relative to the total particle population.

The size and morphology of $\mathrm{N}$-AI liposomes were further confirmed by measurement of liposome diameter from cryogenic transmission electron microscopy (cryo-TEM) images (Figure 1a). The average diameter of $N$-AI liposomes (138.7 $\pm 18.4 \mathrm{~nm}$; Figure $1 \mathrm{~b})$ was similar to that determined using dynamic light scattering $(139.9 \pm 3.9 \mathrm{~nm}$; Table 1$)$. Cryo-TEM additionally revealed $N$-AI liposomes to be spherical, monodisperse, and unilamellar. The concentration of $\mathrm{N}$-AI encapsulated in the liposomes could not be determined by spectrophotometry, as the liposome phospholipid interfered with the peak absorbance of $\mathrm{N}$-AI at $310 \mathrm{~nm}$ and $435 \mathrm{~nm}$ (Supplementary Information Figure S1). Therefore, the concentration of $N$-AI loaded into liposomes was determined by HPLC, which revealed an $N-\mathrm{AI}$ concentration of $2.2 \mathrm{mM}$, equating to a $43.1 \%$ entrapment efficiency based on the starting amount of $\mathrm{N}$-AI used in the liposome preparation (Supplementary Information Figure S2). This translated into $7.3 \% w / w N$-AI loaded per unit weight of the soy PC, indicating the percentage of mass of the liposome that is due to the encapsulated drug. 


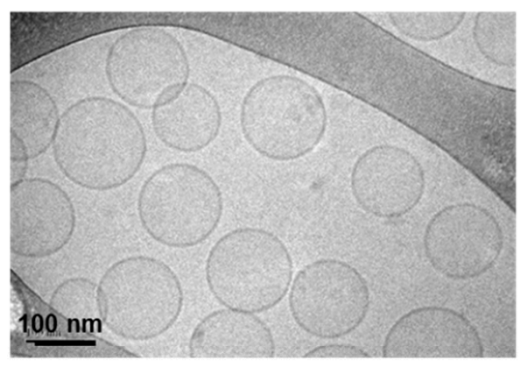

C

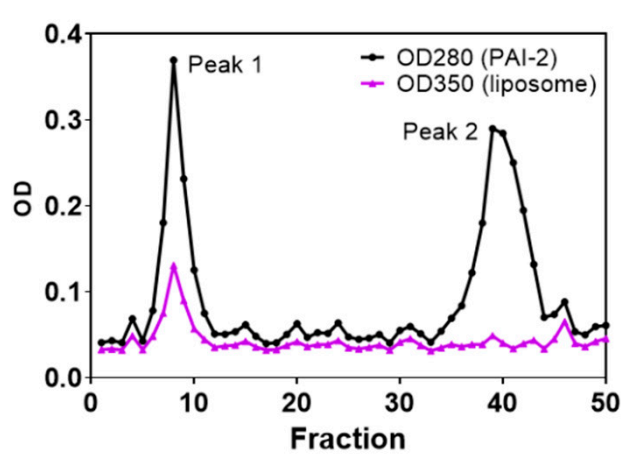

b

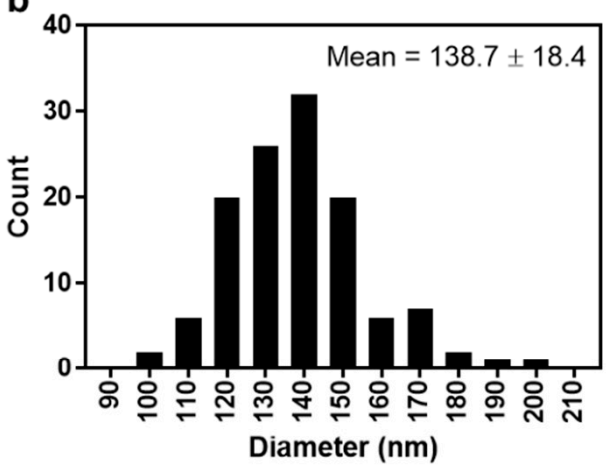

d

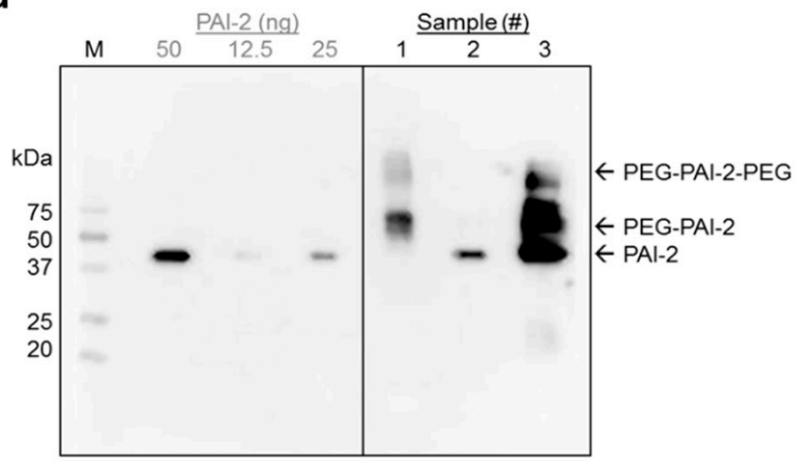

e

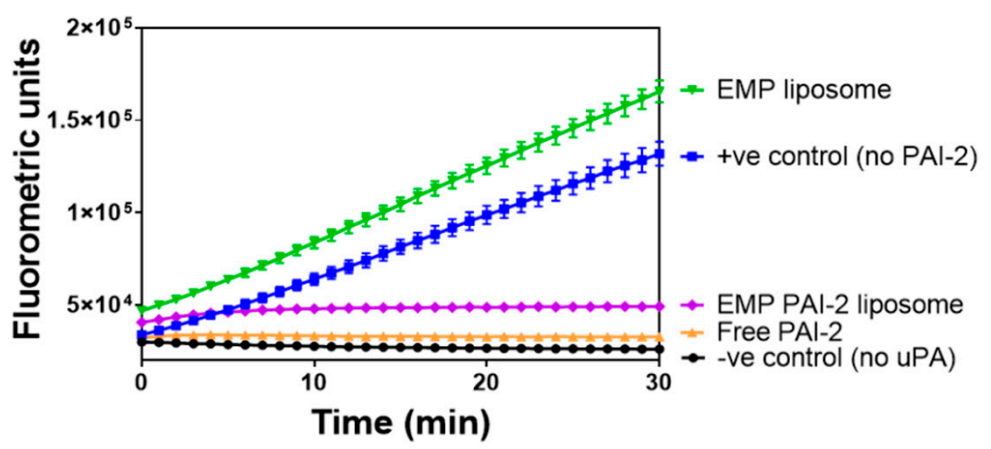

Figure 1. Characterization of N-AI-loaded liposomes. (a) Representative cryo-TEM image of N-AIloaded liposomes. (b) Determination of the average liposome diameter from cryo-TEM image analysis. (c) Size-exclusion chromatograph of the PAI-2 liposome fractions after conjugation, including PAI-2 liposomes (peak 1) and unbound PAI-2 (peak 2). (d) Western blot detection of PAI-2 in size-exclusion fractions (1, 2), un-purified liposomes (3), and purified PAI-2 (50, 25 and $12.5 \mathrm{ng}$ ). OD = optical density, $\mathrm{M}=$ marker, $\mathrm{PEG}=$ polyethylene glycol. (e) Kinetic inhibition curves for unconjugated PAI-2 versus PAI-2 conjugated to empty liposomes (EMP PAI-2), against uPA in solution. Empty liposomes were included as a fluorescence control. Values are means \pm s.d. $(n=3)$.

PAI-2 was incubated with preformed liposomes containing mal-PEG ${ }_{2000}-\mathrm{DSPE}$, to allow conjugation to the liposome surface. Unconjugated PAI-2 was removed using size-exclusion chromatography (SEC; Figure 1c). Analysis of fractions by spectrophotometry revealed that the unconjugated PAI-2 (peak 2) had separated from the covalently attached PAI-2 on the liposome surface (peak 1). As PAI-2 could not be detected or quantified using commercial biochemical protein assays, due to phospholipid interference [34] (data not shown), Western blotting was used to confirm successful conjugation of PAI-2 to liposomes (Figure 1d). Covalent conjugation of PAI-2 to liposome phospholipid (PEG-DSPE; molecular weight $\sim 2940 \mathrm{kDa}$ ) to form PAI-2-PEG-DSPE was confirmed by a lag in gel migration of 
PAI-2 in the peak 1 fraction (sample \#1), relative to the peak 2 fraction (sample \#2), which corresponded to the $45 \mathrm{kDa}$ molecular weight of free PAI-2. The amount of PAI-2 associated with the liposome fraction in sample \#1 was $42 \mathrm{ng}$, after interpolation from a standard curve.

An important step in characterizing ligand-functionalized liposomes was to confirm whether the targeting ligand(s) retain activity against the target receptor once bound to the liposome surface. The uPA inhibitory activity of PAI-2-liposomes was assessed using enzymatic assays. A significant reduction in the rate of FLU was observed for the EMP PAI-2 liposomes (43.5 $\pm 24.9 \mathrm{FLU} / \mathrm{min})$ compared to the EMP liposomes (4026.9 $\pm 206.2 \mathrm{FLU} / \mathrm{min})$ (Figure 1e). EMP PAI-2 liposomes were as effective at inhibiting uPA activity, as the unconjugated PAI-2 (95-100\% inhibition) demonstrating that PAI-2 liposomes were fully active.

\subsection{PAI-2 Liposomes Are Taken up by Cells through RME-Dependent and Non-Dependent Mechanisms}

Prior to assessing cellular uptake, the MCF-7 and MDA-MB-231 breast cancer cell lines were profiled for cell surface uPA and uPAR expression through flow cytometry. MDA-MB-231 cells showed a significantly $(p<0.001)$ higher mean fluorescent intensity for UPAR and uPA (MFI; $11.82 \pm 0.90$ and $6.66 \pm 0.97$, respectively) than MCF-7 cells (MFI; $0.26 \pm 0.03$ and $2.49 \pm 0.10$, respectively; Figure 2a).

The cellular uptake of liposomes was determined by flow cytometry, using FITC-PEG-DSPE incorporated into the liposome bilayer. PAI-2-functionalized (EMP PAI-2; $152.6 \pm 8.7 \mathrm{~nm}$ ) and non-functionalized (EMP; $152.8 \pm 11.7 \mathrm{~nm}$ ) FITC liposomes were incubated with MCF-7 cells (low uPA/uPAR) and MDA-MB-231 cells (high uPA/uPAR) for $45 \mathrm{~min}$. A significant increase in the EMP PAI-2 liposome uptake was observed in the MDA-MB-231 cells at $5 \mathrm{mM}$ and $2.5 \mathrm{mM}$ liposome concentrations ( $p<0.0001$ and $p<0.001$, respectively) relative to the EMP liposomes, but not at $1.25 \mathrm{mM}$ liposome concentration. No significant differences were observed between the uptake of EMP and EMP PAI-2 liposomes in the MCF-7 cells, at any liposome concentrations ( $p>0.05$; Figure $2 \mathrm{~b}$ ).

For the cellular localization of EMP PAI-2 liposomes through confocal microscopy, the intensely fluorescent fluorophore R18 was used to label liposomes. Dynamic light scattering revealed average diameters of $131.3 \pm 2.5 \mathrm{~nm}$ and $131.2 \pm 6.6 \mathrm{~nm}$ for EMP and EMP PAI-2 R18-labelled liposomes, respectively. A strong fluorescent signal from R18-labelled liposomes was detected at the cell membrane, within the cytoplasm and within lysosomes (indicated by colocalization of liposome and LysoTracker), $1 \mathrm{~h}$ post-incubation for both cell lines (Figure 2c), indicating cellular uptake for both EMP PAI-2 liposomes and EMP liposomes.

\subsection{Cytotoxicity of N-AI PAI-2 Liposomes against Breast Cancer Cells}

Treatment of MCF-7 and MDA-MB-231 cells for $72 \mathrm{~h}$ with N-AI PAI-2 liposomes but not EMP PAI-2 liposomes (at an equivalent phospholipid concentration), resulted in a dose-dependent decrease in cell viability for both cell lines, consistent with intracellular delivery of the cytotoxic N-AI (Supplementary Information Figure S3). The cytotoxic effect of N-AI PAI-2 liposomes against MDA-MB-231 cells ( $\mathrm{IC}_{50}$ of $\left.5.40 \pm 1.14 \mu \mathrm{M}\right)$ was significantly greater $(p<0.01)$ than the MCF-7 cells $\left(\mathrm{IC}_{50}\right.$ of $\left.31.84 \pm 8.20 \mu \mathrm{M}\right)$. EMP PAI-2 liposomes elicited some degree of cytotoxicity in both cell lines, at the highest liposome concentrations tested. 
a

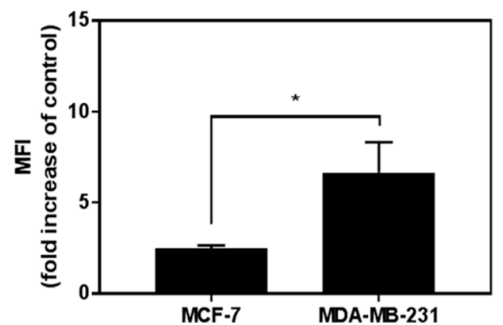

b

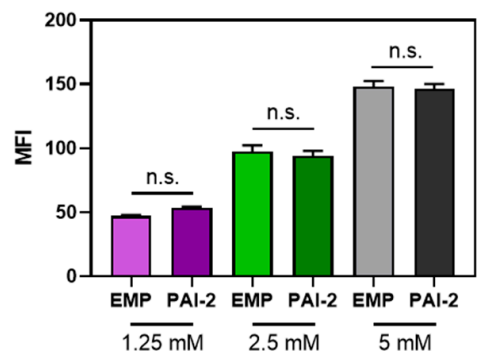

C
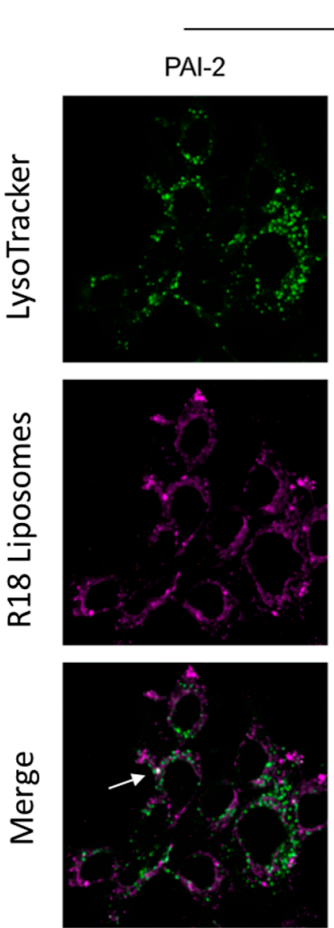

MCF-7

EMP
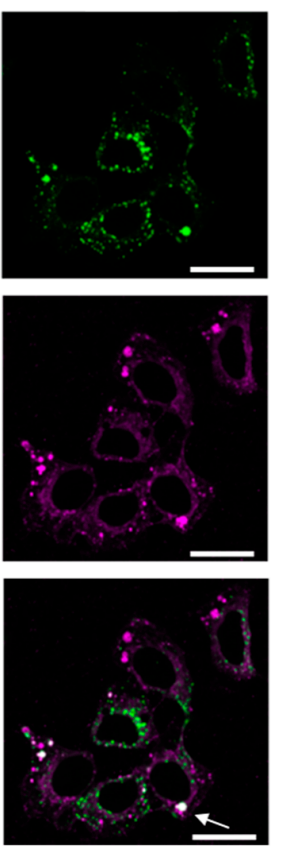

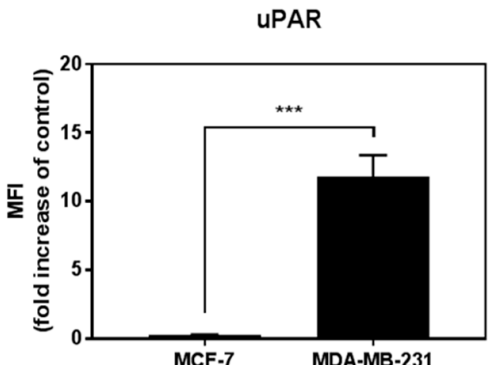

MDA-MB-231

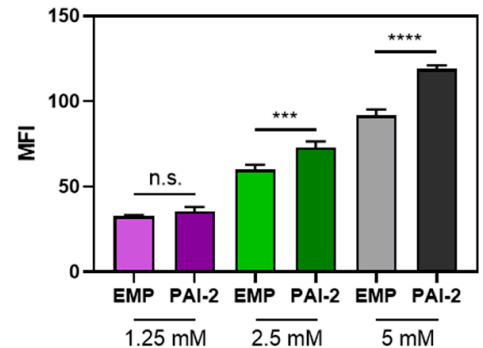

MDA-MB-231

PAI-2
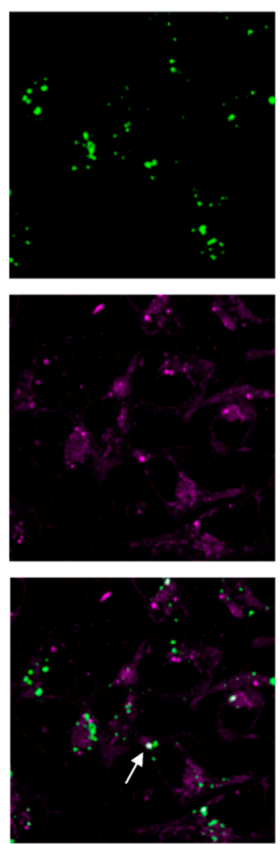

EMP
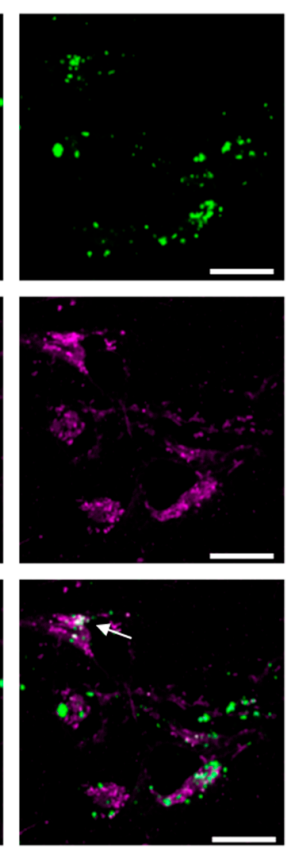

Figure 2. Cell surface expression of uPA/uPAR and cellular uptake of PAI-2 FITC-labelled liposomes by breast cancer cells. (a) MCF-7 cells and MDA-MB-231 cells were incubated with antibodies against human urokinase plasminogen activator (uPA), its receptor (uPAR), or an isotype control antibody (IgG) and cell surface expression analyzed by flow cytometry. (b) MCF-7 cells (left) and MDA-MB-231 cells (right) were incubated with empty non-functionalized (EMP) FITC liposomes or empty PAI-2-functionalized (PAI-2) FITC liposomes for $45 \mathrm{~min}$, and were analyzed by flow cytometry. MFI = mean fluorescence intensity Data are the mean \pm s.d. $(n=3) .{ }^{*}: p<0.05 ;{ }^{* *}: p<0.001$; $* * * *: p<0.0001 ;$ n.s. = not significant $(p>0.05)$. (c) EMP liposomes and PAI-2 liposomes were labelled with R18 and incubated with cells at a liposome concentration of $2.5 \mathrm{mM}$ for $1 \mathrm{~h}$. LysoTracker green was added to visualize lysosomes. Arrows point to white foci, which indicate colocalization of green and magenta signals. Representative images are shown. Scale bars are $25 \mu \mathrm{m}$. 


\subsection{Cytotoxicity of N-AI PAI-2 Liposomes against Breast Cancer Spheroids}

MCF-7 and MDA-MB-231 cells are reported to form spheroids under low-attachment growth conditions [35]. EMP PAI-2 and N-AI PAI-2 liposomes at equivalent phospholipid concentrations were incubated with the preformed spheroids and imaged every $24 \mathrm{~h}$ (Figure 3). Spheroids treated with EMP PAI-2 liposomes showed continued growth and an increase in spheroid diameter, over time. In contrast, treatment with N-AI PAI-2 liposomes showed a time- and concentration-dependent disassembly of the spheroid structure, at concentrations above $62 \mu \mathrm{M}$ for both cell lines (Figure 3a). However, MDA-MB-231 spheroids appeared to be more sensitive to N-AI PAI-2 liposome treatment, which showed clear evidence of spheroid dissociation, as early as $24 \mathrm{~h}$, compared to the MCF-7 spheroids (Figure 3b). By $48 \mathrm{~h}$, the MDA-MB-231 spheroids were almost completely dissociated in contrast to MCF-7 spheroids. A comparison of the Calcein AM stained spheroids after $96 \mathrm{~h}$ found MDA-MB-231 spheroids treated with N-AI and N-AI PAI-2 to be fully dissociated, while the MCF-7 spheroids, although smaller than the control (EMP and EMP PAI-2), remained largely intact (Figure 3c).

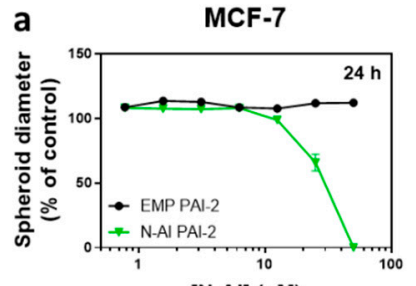

[N-Al] $(\mu \mathrm{M})$
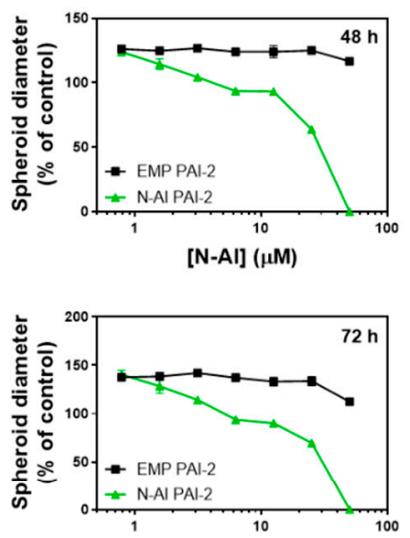

[N-Al] ( $\mu \mathrm{M})$

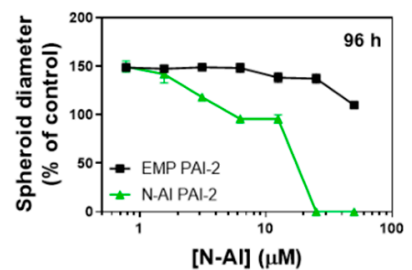

MDA-MB-231

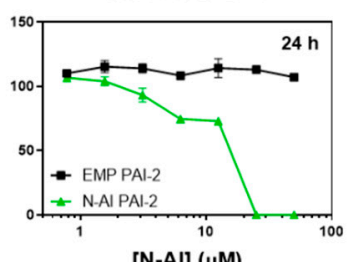

[N-AI] ( $\mu \mathrm{M})$
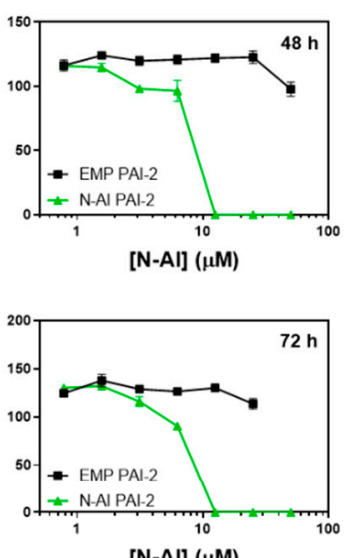

[N-Al] $(\mu \mathrm{M})$

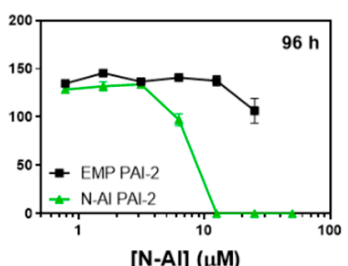

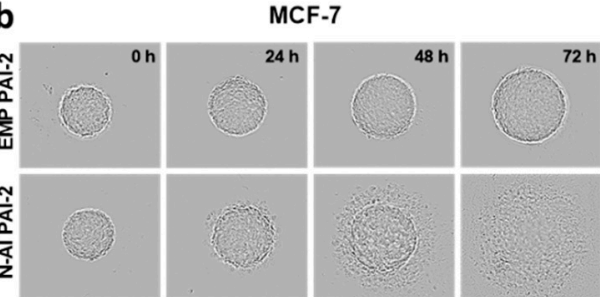

MDA-MB-231

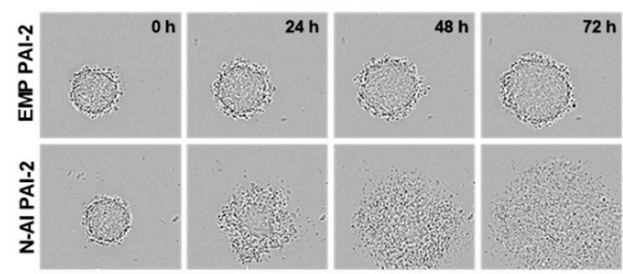

C

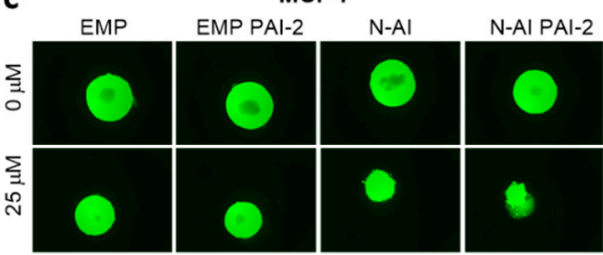

MDA-MB-231

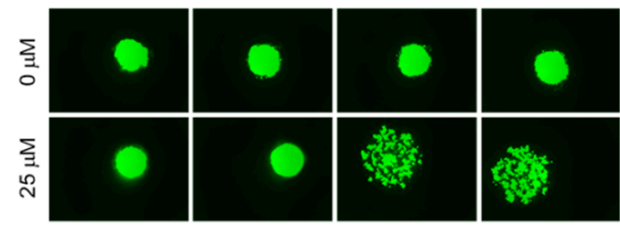

Figure 3. Cytotoxic effect of N-AI PAI-2 liposomes on breast cancer spheroids. (a) Spheroid diameter was measured after incubation with EMP PAI-2 liposomes or N-AI PAI-2 liposomes with MCF-7 and MDA-MB-231 multicellular tumor spheroids, over a period of $96 \mathrm{~h}$. (b) Representative bright-field images and (c) fluorescent images, following the addition of calcein-AM to visualize the viable cells were captured at the same magnification $(n=3)$. Spheroids in $(\mathbf{b}, \mathbf{c})$ were treated with $25 \mu \mathrm{M} \mathrm{N}$-AI or the equivalent concentration of phospholipid in liposomal formulation. Scale bars are $100 \mu \mathrm{m}$. Data are the mean \pm s.d. $(n=3)$. 


\subsection{Pharmacokinetics and Biodistribution of N-AI PAI-2 Liposomes}

To determine the pharmacokinetic and organ distribution profiles of $\mathrm{N}$-AI liposomes and $\mathrm{N}$-AI PAI-2 liposomes in tumor-bearing mice, liposomes were labelled with tritiated cholesteryl hexadecyl ether $\left({ }^{3} \mathrm{H}-\mathrm{CHE}\right)$, to enable their detection in plasma and tissues, through liquid scintillation counting. Liposomes were monodispersed with average diameters of $115 \pm 34 \mathrm{~nm}$ and $117 \pm 39 \mathrm{~nm}$, for $N$-AI and N-AI PAI-2 liposomes, respectively. Scintillation counts of the two liposome stock preparations were $319,698 \mathrm{CPM} / \mathrm{ml}$ and 312,163 CPM/ml for N-AI and N-AI PAI-2 liposomes, respectively. The plasma half-life was determined to be $5.63 \mathrm{~h}$ and $5.82 \mathrm{~h}$ for the $\mathrm{N}$-AI and $\mathrm{N}$-AI PAI-2 liposomes, respectively (Figure 4a). The plasma clearance profiles of the two liposomes and the pharmacokinetic parameters from the curve-fitting analysis were not significantly different $(p>0.05)$ (Table 2).
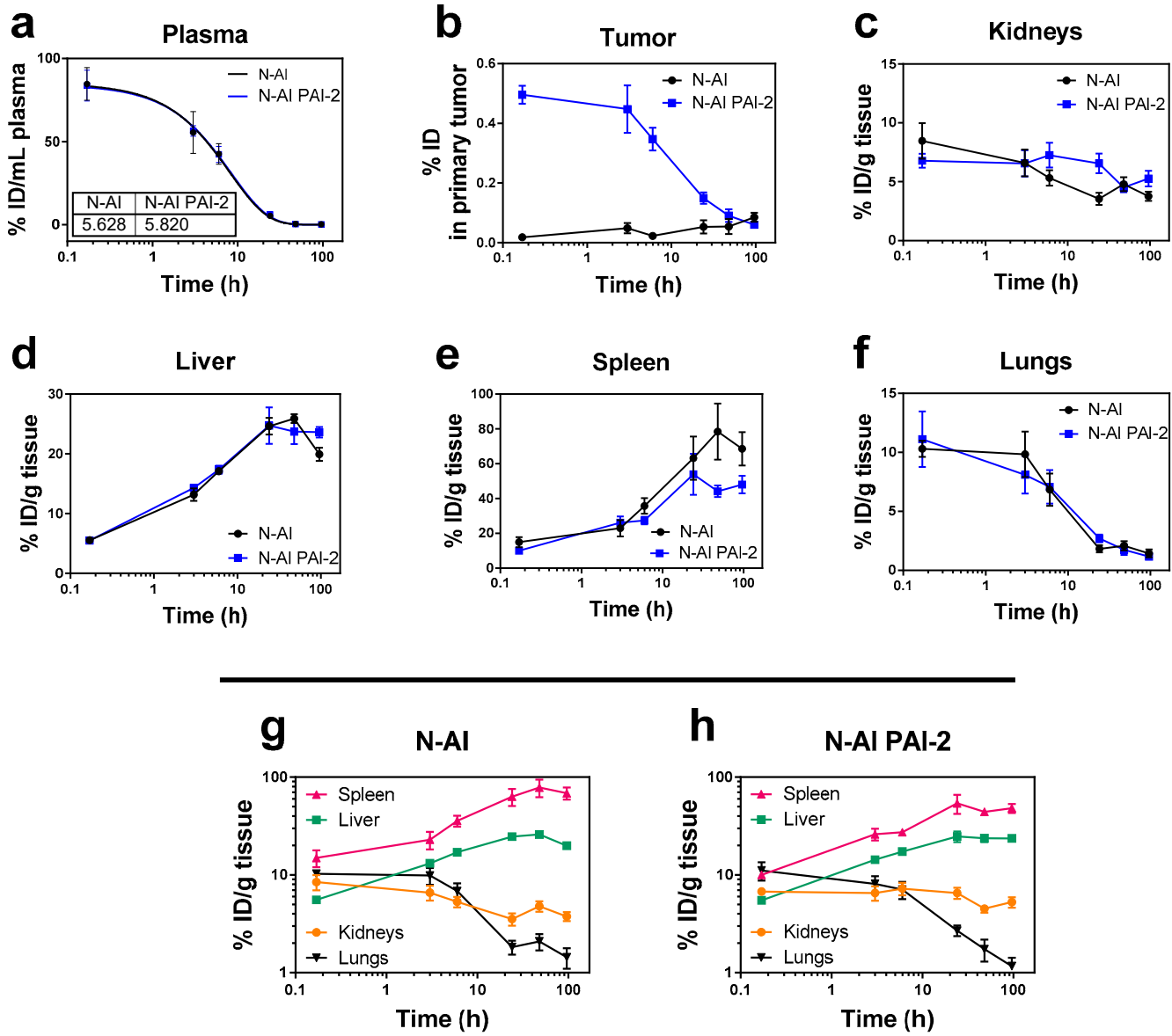

Figure 4. Biodistribution and pharmacokinetics of the radiolabeled liposomes in mice. $\mathrm{N}$-AI and $\mathrm{N}$-AI PAI-2 liposomes were labeled with tritiated cholesteryl hexadecyl ether $\left({ }^{3} \mathrm{H}-\mathrm{CHE}\right)$ and administered intravenously as a single bolus dose. Tritiated signal was measured in the (a) plasma, (b) tumor, (c) kidneys, (d) liver, (e) spleen, and (f) lungs at each time-point. Kidney, liver, spleen, and lung data are also presented on the same graph for the (g) N-AI liposomes and (h) N-AI PAI-2 liposomes, for biodistribution comparison. Results are expressed as the percentage of injected dose (ID) per gram of tissue or milliliter of plasma, and as the percentage of the injected dose (ID) in the whole analyzed primary tumor. Values are the mean \pm s.e.m. $(n=4)$. 
Table 2. Pharmacokinetic parameters of N-AI and N-AI PAI-2 liposomes. N-AI and N-AI PAI-2 liposomes were labeled with tritiated cholesteryl hexadecyl ether $\left({ }^{3} \mathrm{H}-\mathrm{CHE}\right)$ and administered intravenously as a single bolus dose. ${ }^{3} \mathrm{H}-\mathrm{CHE}$ signal was measured in plasma at each time-point to determine the following parameters.

\begin{tabular}{ccc}
\hline PK Parameter & $N$-AI & $N$-AI PAI-2 \\
\hline $\mathrm{C}_{\max }(\% \mathrm{ID} / \mathrm{mL})$ & $84.66( \pm 9.79)$ & $83.76( \pm 9.25)$ \\
$\mathrm{K}_{\mathrm{elim}} \alpha$ (fast) $\mathrm{min}^{-1}$ & 0.061 & 0.058 \\
$\mathrm{~K}_{\mathrm{elim}} \beta$ (slow) $\mathrm{min}^{-1}$ & 0.002 & 0.002 \\
$\mathrm{~T}_{1 / 2} \alpha$ (fast) $\mathrm{min}$ & 11.419 & 12.050 \\
$\mathrm{~T}_{1 / 2} \beta$ (slow) min & 408.152 & 410.843 \\
Correlation coefficient $\left(\mathrm{R}^{2}\right)$ & 0.9629 & 0.9836 \\
$\mathrm{AUC}(\% \mathrm{ID} / \mathrm{min} / \mathrm{mL})$ & $860.3( \pm 66.89)$ & $873.4( \pm 50.79)$ \\
\hline
\end{tabular}

At $24 \mathrm{~h}, 48 \mathrm{~h}$, and $96 \mathrm{~h}$, tumor uptake of the N-AI and N-AI PAI-2 liposomes was not significantly different $(p>0.05)$. Liposome accumulation in the kidneys, liver, spleen, and lungs at each time-point was similar between the N-AI and N-AI PAI-2 liposomes (Figure 4c-f). The trends indicated increased clearance via the liver and spleen, over time, with clearance via the kidneys and accumulation in the lungs was minimal for both liposome formulations (Figure $4 \mathrm{~g}-\mathrm{h}$ ).

Tumors were removed from mice and analyzed for tritiated liposome signal. The results showed rapid accumulation of $\mathrm{N}$-AI PAI-2 liposome signal in tumors, compared to $\mathrm{N}$-AI liposomes, as indicated by the significantly increased \%ID at $10 \mathrm{~min}, 3 \mathrm{~h}$, and $6 \mathrm{~h}$ post-injection $(p<0.001$; Figure $4 \mathrm{~b})$.

\subsection{Maximum Tolerated Dose of N-AI-Loaded Liposomes in Mice}

$\mathrm{N}$-AI liposomes were well-tolerated in mice, when given as an intravenous (i.v.) single bolus dose up to $20 \mathrm{mg} / \mathrm{kg} \mathrm{N}$-AI or multiple fractionated dose, up to $100 \mathrm{mg} / \mathrm{kg} \mathrm{N}$-AI. This exceeded that of free $N$-AI, which had a maximum tolerated single bolus dose of $8.5 \mathrm{mg} / \mathrm{kg}$ (Supplementary Information Figure S4). Mice treated with free drug at concentrations above $8.5 \mathrm{mg} / \mathrm{kg}$, as well as the equivalent volume of the DMSO/PBS vehicle without drug, displayed adverse signs of intolerance immediately upon injection, including lethargy, hind-leg paralysis, tremors, and difficulty breathing [36,37], preventing higher concentrations of free N-AI from being tested. Liposome encapsulation therefore provided an injectable formulation of $\mathrm{N}-\mathrm{AI}$, with improved tolerability than the free drug.

\section{Discussion}

The uPA system is recognized to play a central role in the ability of breast cancer cells to escape the primary site of the tumor and colonize other parts of the body. Hence, targeting this system using novel approaches might be effective in the treatment of highly invasive or metastatic breast cancer. This work aimed to improve upon the solubility and delivery of the potent $N$-alkylisatin $(N-A I)$ cytotoxin to uPA/uPAR positive breast cancer cells, through the conjugation of PAI-2 to the surface of PEGylated $N$-AI-loaded liposomes.

The successful encapsulation of a hydrophobic drug into liposomes can greatly enhance the aqueous solubility and bioavailability of the molecule, and therefore increase the suitability for its use in parenteral drug delivery applications. With a logarithmic octanol/water partition coefficient $(\log P)$ of 3.39, the aqueous solubility of non-liposomal N-AI is negligible. In this work, the thin film hydration method was successfully used to load N-AI into the bilayer of soy PC PEGylated liposomes, to achieve a final $\mathrm{N}$-AI concentration of $2.2 \mathrm{mM}$ in aqueous solution. $\mathrm{N}$-AI was substituted for cholesterol in the formulation, in order to increase the drug-loading capacity of $\mathrm{N}-\mathrm{AI}$ in the bilayer. As the molecular weight of $\mathrm{N}$-AI and cholesterol were similar, and both were hydrophobic molecules, we achieved a greater encapsulation of $\mathrm{N}-\mathrm{AI}$ in the liposomes, in the absence of cholesterol, without affecting the zeta potential, liposome size, or stability (Supplementary Information Figure S5). 
The zeta potential of liposomes is dependent on a number of factors [38], while PEG itself does not affect the surface charge of liposomes, PEG-DSPE introduces a negative surface potential due to the phosphate diester moiety [39]. In this study, liposomes displayed a slightly negative, but near-neutral, zeta potential, which did not vary greatly with $\mathrm{N}$-AI encapsulation or PAI-2 conjugation to the liposome surface. Although it was noted that PAI-2-functionalized liposomes were slightly more negative than the non-functionalized liposomes, as PAI-2 has a predicted isoelectric point of 5.4 and therefore a negative charge at physiological $\mathrm{pH}$ [40]. It was reported that liposomes with mildly charged or near-neutral surfaces show a propensity to aggregate faster than liposomes with a strong surface charge, as the latter show a greater particle-particle repulsion and hence are more electrostatically stabilized in suspension [41]. However, our liposome formulations were found to be remarkably stable with no aggregation detected or drug leakage under the storage conditions for $>4$ weeks (data not shown).

The optimization of surface-functionalized liposomes through the covalent attachment of targeting moieties to the outer lipid leaflet is complex. According to a recent study by Herda et al., only $3.5 \%$ of proteins attached to the surface of $\mathrm{SiO}_{2}-\mathrm{PEG}_{8}-\mathrm{Tf}$ particles had appropriate orientation for receptor recognition [42]. Furthermore, increasing antibody density on the surface of nanoparticles was found to reduce receptor-dependent targeting [43]. In this study, the conjugation of PAI-2 to the surface of liposomes was confirmed by Western blotting and the maintenance of PAI-2 inhibitory activity post-conjugation was validated by uPA assay. PAI-2-liposomes were as effective at inhibiting the enzymatic activity of uPA as the unconjugated PAI-2, demonstrating that PAI-2 liposomes were fully active. While Western Blotting was successful in qualitatively confirming the conjugation of PAI-2 to liposomes and in confirming the absence of unconjugated PAI-2 in the purified liposome, the use of emerging methods such as single molecule fluorescent imaging to quantify ligand density on the liposome surface would enable a more precise characterization of targeted liposome formulations [44].

As reported previously, cell surface UPA and UPAR expression is low in MCF-7 cells relative to the MDA-MB-231 cells [12,45]. This difference in uPAR expression was associated with a significant increase in fluorescently labelled EMP PAI-2 liposome uptake, relative to the non-functionalized EMP liposomes by MDA-MB-231 cells, but not by MCF-7 cells. Liposomes can be taken into cells via several different mechanisms, including adsorption, lipid exchange, intracellular membrane fusion, and receptor-mediated endocytosis (RME) [46]. The presence of a fluorescent signal from cells treated with EMP fluorescently labelled liposomes indicates that these liposomes were taken up into cells by fusion or other non-specific mechanisms, rather than by RME. In contrast, the uptake of EMP PAI-2 liposomes by the MDA-MB-231 cells was greater than the uptake of EMP liposomes in MDA-MB-213 cells. As the average liposome diameters of the FITC-labelled EMP and EMP PAI-2 liposomes were equivalent, this difference in uptake was likely due to the presence of PAI-2 at the liposome surface and interaction with uPA/uPAR overexpressed on the surface of MDA-MB-231 cells. Competition binding studies using excess PAI-2 or uPAR antibody could be used to further confirm this mechanism $[47,48]$, however, the uPA/uPAR-dependent uptake of PAI-2 has been extensively characterized by our group [18-20,49] and others [50]. Studies assessing the colocalization of liposome signal with lysosomes through confocal microscopy, further confirmed that liposomes were indeed internalized by cells and accumulated in lysosomes, in addition to being present elsewhere in the cell. This result was not unexpected, given that the liposomes were incubated with cells at a high phospholipid concentration, creating an environment where liposomes in solution would passively fuse with cell membranes over time [46]. Collectively, our results indicate that EMP and EMP PAI-2 liposomes are taken into cells via a number of mechanisms, including RME.

In the multicellular tumor spheroid experiments, imaging of spheroids over $96 \mathrm{~h}$ indicated a concentration- and time-dependent destruction of both MCF-7 and MDA-MB-231 spheroids, when treated with N-AI PAI-2 liposomes. However, MDA-MB-231 spheroids treated with N-AI PAI-2 liposomes showed a greater destruction of the spheroid architecture than MCF-7 spheroids at lower N-AI PAI-2 liposome concentrations and at earlier time-points. We posit that this effect was receptor-dependent, due to the uPA/uPAR targeting of PAI-2 functionalized liposomes, but acknowledge that it might also 
be the result of differences in cellular adhesion molecules involved in spheroid formation and cell-cell interactions between the two cell lines [51], thereby influencing liposome perfusion. While spheroid models are increasingly used to study anti-tumor drug effects, a major limitation is that they mimic only the avascular region of in vivo tumors, and exclude important aspects of tumorigenesis, such as the vasculature, immune system, and fluid dynamics. This is especially important in the context of evaluating the efficacy of nanomedicines, where the enhanced permeability and retention (EPR) effect is likely at play and vascular permeability is a relevant factor in their accumulation at the tumor site.

Determining the in vivo properties of novel nanotherapies is important for evaluating how a new nanoparticle formulation can be expected to perform in humans. In this work, the pharmacokinetics and tissue distribution of N-AI and N-AI PAI-2 liposomes were evaluated in an orthotropic MDA-MB-231 breast tumor xenograft mouse model. The addition of PAI- 2 to the surface of $\mathrm{N}$-AI-loaded liposomes did not significantly alter the in vivo blood clearance properties of the formulation, but did increase accumulation of liposomes at the primary tumor site relative to non-functionalized liposomes. The PEGylated liposome formulation contained $10 \mathrm{~mol} \%$ PEG-DSPE and ranged between $130 \mathrm{~nm}$ and $150 \mathrm{~nm}$ in diameter. This liposome size range and PEG density has been reported to avoid rapid clearance by the mononuclear phagocyte system (MPS) in circulation, and to utilize the EPR effect to extravasate and accumulate at the site of tumors for drug delivery [42]. The accumulation of nanoparticles in tumors via EPR is dependent on a number of factors, including interstitial fluid pressure, vascularity of the tumor, and the in vivo circulation time of the nanoparticle formulation [52]. As the plasma half-lives of the two liposomes were largely equivalent, the presence of PAI-2 at the liposome surface might have affected liposome extravasation and uptake at the tumor site, with PAI-2 liposomes binding to uPAR expressed by tumor cells, as was observed in the in vitro experiments. The difference in uptake might also be due to slight differences in surface charge. Surface charge was previously shown to affect tumor uptake of nanoparticles [48], whereby histological analysis showed that negatively charged and neutral liposomes are able to extravasate at the site of the tumor, while positively charged liposomes remain associated with the vascular endothelium, limiting their suitability for tumor-targeting applications [53].

Finally, the maximum tumor accumulation of the liposomes reported in this study was $0.5 \%$ of the ID at the 10 min time-point for $\mathrm{N}$-AI PAI-2 liposomes and $0.02 \%$ for $\mathrm{N}$-AI liposomes. These values were comparable to other PEGylated nanoparticles, which typically showed $1 \%$ or less of the total ID reaching the site of the primary tumor. Notably, the high tumor accumulation of Doxil ${ }^{\circledR}$ in humans (reported as high as $10 \%$ of the ID) was due in large part to the very long circulation half-life (up to $45 \mathrm{~h}$ ) of the formulation [54]. Given that the in vivo half-life of $\mathrm{N}$-AI PAI-2 liposomes was $5.82 \mathrm{~h}$, modifications to the 'stealth' coating of liposomes to promote increased blood circulation and reduce MPS clearance, might further improve liposome uptake into tumors. Following systemic administration, the surface of PEGylated liposomes is modified by protein adsorption, forming a protein corona. Future studies should also aim to characterize the composition of the protein corona, before conducting in vivo efficacy studies, in order to further understand the mechanism of tumor uptake.

\section{Conclusions}

This work supports the rationale for targeting uPAR-positive breast cancer cells, using N-AI-loaded PAI-2-functionalized liposomes, and provides a basis for the further development of liposomes that can target heterogeneous tumor cells within the TNBC subtype, in which uPAR was shown to play a key role in driving metastasis. Further research is needed to clarify if and how the potency of $\mathrm{N}$-AI as a cytotoxin could be translated into an anti-tumor growth effect by targeting uPAR-positive tumors. The utilization of advanced preclinical models and methods will enable an enhanced evaluation of $\mathrm{N}$-AI PAI-2 liposomes in the in vivo context. Future studies assessing the efficacy of N-AI PAI-2 liposomes in TNBC are therefore warranted. 
Supplementary Materials: The following are available online at http://www.mdpi.com/1999-4923/12/7/641/s1. Figure S1: Liposome phospholipid interference with N-AI absorption spectrum. Figure S2: HPLC standard curve for quantifying N-AI encapsulated in liposomes. Figure S3: Cytotoxicity of N-AI PAI-2 liposomes. Figure S4: Toxicology testing of empty and N-AI-loaded liposomes in mice. Figure S5: Stability of N-AI-loaded liposomes over time.

Author Contributions: Conceptualization, K.L.V.; methodology, L.B. and K.L.V.; validation, L.B.; formal analysis, L.B. and K.L.V.; investigation, L.B. and K.L.V.; resources, M.R. and K.L.V.; writing - original draft preparation, L.B. and K.L.V.; writing-review and editing, L.B., D.N.S, M.R. and K.L.V.; visualization, L.B., K.L.V.; supervision, M.R., D.N.S. and K.L.V.; project administration, K.L.V.; funding acquisition, K.L.V. All authors have read and agreed to the published version of the manuscript.

Funding: This research was funded by Cure Cancer Australia Foundation with the award of Young Investigator Project Grant to K.L.V., administered by Cancer Australia as part of the Priority-driven Collaborative Cancer Research Scheme, APP1045831. The APC was funded by Molecular Horizons, University of Wollongong.

Acknowledgments: This research was conducted with the support of an Australian Government Research Training Program Scholarship, and a Jayne Wilson Cancer Research PhD Top-Up Scholarship (UOW) awarded to L.B.

Conflicts of Interest: The authors declare no conflict of interest. The funders had no role in the design of the study; in the collection, analyses, or interpretation of data; in the writing of the manuscript, or in the decision to publish the results.

\section{References}

1. Jemal, A.; Bray, F.; Center, M.M.; Ferlay, J.; Ward, E.; Forman, D. Global cancer statistics. CA Cancer J. Clin. 2011, 61, 69-90. [CrossRef]

2. Ward, E.M.; DeSantis, C.E.; Lin, C.C.; Kramer, J.L.; Jemal, A.; Kohler, B.; Brawley, O.W.; Gansler, T. Cancer statistics: Breast cancer in situ. CA Cancer J. Clin. 2015, 65, 481-495. [CrossRef] [PubMed]

3. Giannopoulou, I.; Mylona, E.; Kapranou, A.; Mavrommatis, J.; Markaki, S.; Zoumbouli, C.; Keramopoulos, A.; Nakopoulou, L. The prognostic value of the topographic distribution of uPAR expression in invasive breast carcinomas. Cancer Lett. 2007, 246, 262-267. [CrossRef] [PubMed]

4. Indira Chandran, V.; Eppenberger-Castori, S.; Venkatesh, T.; Vine, K.L.; Ranson, M. HER2 and uPAR cooperativity contribute to metastatic phenotype of HER2-positive breast cancer. Oncoscience 2015, 2, 207-224. [CrossRef] [PubMed]

5. Ranson, M.; Andronicos, N.M. Plasminogen binding and cancer: Promises and pitfalls. Front. Biosci. J. Virtual Libr. 2003, 8, s294-s304. [CrossRef] [PubMed]

6. Harris, L.; Fritsche, H.; Mennel, R.; Norton, L.; Ravdin, P.; Taube, S.; Somerfield, M.R.; Hayes, D.F.; Bast, R.C. American Society of Clinical Oncology 2007 update of recommendations for the use of tumor markers in breast cancer. J. Clin. Oncol. Off. J. Am. Soc. Clin. Oncol. 2007, 25, 5287-5312. [CrossRef]

7. Duffy, M.J.; McGowan, P.M.; Harbeck, N.; Thomssen, C.; Schmitt, M. uPA and PAI-1 as biomarkers in breast cancer: Validated for clinical use in level-of-evidence-1 studies. Breast Cancer Res. 2014, 16, 428. [CrossRef]

8. Urban, P.; Vuaroqueaux, V.; Labuhn, M.; Delorenzi, M.; Wirapati, P.; Wight, E.; Senn, H.J.; Benz, C.; Eppenberger, U.; Eppenberger-Castori, S. Increased expression of urokinase-type plasminogen activator mRNA determines adverse prognosis in ErbB2-positive primary breast cancer. J. Clin. Oncol. Off. J. Am. Soc. Clin. Oncol. 2006, 24, 4245-4253. [CrossRef]

9. Bianchi, E.; Cohen, R.L.; Thor, A.T.; Todd, R.F.; Mizukami, I.F.; Lawrence, D.A.; Ljung, B.M.; Shuman, M.A.; Smith, H.S. The urokinase receptor is expressed in invasive breast cancer but not in normal breast tissue. Cancer Res. 1994, 54, 861-866.

10. Brungs, D.; Chen, J.; Aghmesheh, M.; Vine, K.L.; Becker, T.M.; Carolan, M.G.; Ranson, M. The urokinase plasminogen activation system in gastroesophageal cancer: A systematic review and meta-analysis. Oncotarget 2017, 8, 23099-23109. [CrossRef]

11. Harris, N.L.E.; Vennin, C.; Conway, J.R.W.; Vine, K.L.; Pinese, M.; Cowley, M.J.; Shearer, R.F.; Lucas, M.C.; Herrmann, D.; Allam, A.H.; et al. SerpinB2 regulates stromal remodelling and local invasion in pancreatic cancer. Oncogene 2017, 36, 4288-4298. [CrossRef] [PubMed]

12. Huber, M.C.; Mall, R.; Braselmann, H.; Feuchtinger, A.; Molatore, S.; Lindner, K.; Walch, A.; Gross, E.; Schmitt, M.; Falkenberg, N.; et al. uPAR enhances malignant potential of triple-negative breast cancer by directly interacting with uPA and IGF1R. BMC Cancer 2016, 16, 615. [CrossRef] [PubMed] 
13. Aubele, M.; Huber, M.C.; Falkenberg, N.; Gross, E.; Braselmann, H.; Walch, A.K.; Schmitt, M. uPA receptor and its interaction partners: Impact as potential therapeutic targets in triple-negative breast cancer. J. Clin. Oncol. 2015, 33, 150. [CrossRef]

14. Al-Mahmood, S.; Sapiezynski, J.; Garbuzenko, O.B.; Minko, T. Metastatic and triple-negative breast cancer: Challenges and treatment options. Drug Deliv. Transl. Res. 2018, 8, 1483-1507. [CrossRef] [PubMed]

15. Keam, B.; Im, S.A.; Kim, H.J.; Oh, D.Y.; Kim, J.H.; Lee, S.H.; Chie, E.K.; Han, W.; Kim, D.W.; Moon, W.K.; et al. Prognostic impact of clinicopathologic parameters in stage II/III breast cancer treated with neoadjuvant docetaxel and doxorubicin chemotherapy: Paradoxical features of the triple negative breast cancer. BMC Cancer 2007, 7, 203. [CrossRef] [PubMed]

16. Mazar, A.P.; Ahn, R.W.; O'Halloran, T.V. Development of Novel Therapeutics Targeting the Urokinase Plasminogen Activator Receptor (uPAR) and Their Translation toward the Clinic. Curr. Pharm. Des. 2011, 17, 1970-1978. [CrossRef]

17. Matthews, H. Synthesis and Biological Evaluation of Plasminogen Activation Inhibitors as Antitumour/ Antimetastasis Agents. Ph.D. Thesis, University of Wollongong, Wollongong, Australia, 2011.

18. Al-Ejeh, F.; Croucher, D.; Ranson, M. Kinetic analysis of plasminogen activator inhibitor type-2: Urokinase complex formation and subsequent internalisation by carcinoma cell lines. Exp. Cell Res. 2004, 297, 259-271. [CrossRef]

19. Croucher, D.; Saunders, D.N.; Ranson, M. The urokinase/PAI-2 complex: A new high affinity ligand for the endocytosis receptor low density lipoprotein receptor-related protein. J. Biol. Chem. 2006, 281, 10206-10213. [CrossRef]

20. Cochran, B.J.; Croucher, D.R.; Lobov, S.; Saunders, D.N.; Ranson, M. Dependence on endocytic receptor binding via a minimal binding motif underlies the differential prognostic profiles of SerpinE1 and SerpinB2 in cancer. J. Biol. Chem. 2011, 286, 24467-24475. [CrossRef]

21. Stutchbury, T.K.; Al-Ejeh, F.; Stillfried, G.E.; Croucher, D.R.; Andrews, J.; Irving, D.; Links, M.; Ranson, M. Preclinical evaluation of 213Bi-labeled plasminogen activator inhibitor type 2 in an orthotopic murine xenogenic model of human breast carcinoma. Mol. Cancer Ther. 2007, 6, 203-212. [CrossRef]

22. Vine, K.L.; Locke, J.M.; Ranson, M.; Pyne, S.G.; Bremner, J.B. An Investigation into the Cytotoxicity and Mode of Action of Some Novel N-Alkyl-Substituted Isatins. J. Med. Chem. 2007, 50, 5109-5117. [CrossRef] [PubMed]

23. Vine, K.L.; Belfiore, L.; Jones, L.; Locke, J.M.; Wade, S.; Minaei, E.; Ranson, M. N-alkylated isatins evade P-gp mediated efflux and retain potency in MDR cancer cell lines. Heliyon 2016, 2, e00060. [CrossRef] [PubMed]

24. Keenan, B.; Finol-Urdaneta, R.K.; Hope, A.; Bremner, J.B.; Kavallaris, M.; Lucena-Agell, D.; Oliva, M.A.; Diaz, J.F.; Vine, K.L. N-alkylisatin-based microtubule destabilizers bind to the colchicine site on tubulin and retain efficacy in drug resistant acute lymphoblastic leukemia cell lines with less in vitro neurotoxicity. Cancer Cell Int. 2020, 20, 170. [CrossRef] [PubMed]

25. Vine, K.L.; Chandran, V.I.; Locke, J.M.; Matesic, L.; Lee, J.; Skropeta, D.; Bremner, J.B.; Ranson, M. Targeting Urokinase and the Transferrin Receptor with Novel, Anti-Mitotic N-Alkylisatin Cytotoxin Conjugates Causes Selective Cancer Cell Death and Reduces Tumor Growth. Curr. Cancer Drug Targets 2012, 12, 64-73. [CrossRef] [PubMed]

26. Grimaldi, N.; Andrade, F.; Segovia, N.; Ferrer-Tasies, L.; Sala, S.; Veciana, J.; Ventosa, N. Lipid-based nanovesicles for nanomedicine. Chem. Soc. Rev. 2016, 45, 6520-6545. [CrossRef] [PubMed]

27. Gubernator, J. Active methods of drug loading into liposomes: Recent strategies for stable drug entrapment and increased in vivo activity. Expert Opin. Drug Deliv. 2011, 8, 565-580. [CrossRef]

28. Uster, P.S.; Allen, T.M.; Daniel, B.E.; Mendez, C.J.; Newman, M.S.; Zhu, G.Z. Insertion of poly(ethylene glycol) derivatized phospholipid into pre-formed liposomes results in prolonged in vivo circulation time. FEBS Lett. 1996, 386, 243-246. [CrossRef]

29. Messerschmidt, S.K.; Kolbe, A.; Muller, D.; Knoll, M.; Pleiss, J.; Kontermann, R.E. Novel single-chain Fv' formats for the generation of immunoliposomes by site-directed coupling. Bioconj. Chem. 2008, 19, 362-369. [CrossRef]

30. Belfiore, L.; Saunders, D.N.; Ranson, M.; Thurecht, K.J.; Storm, G.; Vine, K.L. Towards clinical translation of ligand-functionalized liposomes in targeted cancer therapy: Challenges and opportunities. J. Control. Release 2018, 277, 1-13. [CrossRef] 
31. Wilhelm, S.; Tavares, A.J.; Dai, Q.; Ohta, S.; Audet, J.; Dvorak, H.F.; Chan, W.C.W. Analysis of nanoparticle delivery to tumours. Nat. Rev. Mater. 2016, 1, 16014. [CrossRef]

32. Liu, F.T.; Rabinovich, G.A. Galectins as modulators of tumour progression. Nat. Rev. Cancer 2005, 5, $29-41$. [CrossRef]

33. Belfiore, L.; Spenkelink, L.M.; Ranson, M.; van Oijen, A.M.; Vine, K.L. Quantification of ligand density and stoichiometry on the surface of liposomes using single-molecule fluorescence imaging. J. Control. Release 2018, 278, 80-86. [CrossRef]

34. Kessler, R.J.; Fanestil, D.D. Interference by lipids in the determination of protein using bicinchoninic acid. Anal. Biochem. 1986, 159, 138-142. [CrossRef]

35. Friedrich, J.; Seidel, C.; Ebner, R.; Kunz-schughart, L.A. Spheroid-based drug screen: Considerations and practical approach. Nat. Protoc. 2009, 4, 309-324. [CrossRef] [PubMed]

36. Caujolle, F.M.; Caujolle, D.H.; Cros, S.B.; Calvet, M.M. Limits of toxic and teratogenic tolerance of dimethyl sulfoxide. Ann. N. Y. Acad. Sci. 1967, 141, 110-126. [CrossRef] [PubMed]

37. Biological Actions and Medical Applications of Dimethyl Sulfoxide; Annals of the New York Academy of Sciences: New York, NY, USA, 1983; Volume 411, pp. 1-404.

38. Smith, M.C.; Crist, R.M.; Clogston, J.D.; McNeil, S.E. Zeta potential: A case study of cationic, anionic, and neutral liposomes. Anal. Bioanal. Chem. 2017, 409, 5779-5787. [CrossRef] [PubMed]

39. Barenholz, Y. Doxil(R) - The first FDA-approved nano-drug: Lessons learned. J. Control. Release 2012, 160, 117-134. [CrossRef]

40. Croucher, D.R.; Saunders, D.N.; Stillfried, G.E.; Ranson, M. A structural basis for differential cell signalling by PAI-1 and PAI-2 in breast cancer cells. Biochem. J. 2007, 408, 203-210. [CrossRef] [PubMed]

41. Safhi, M.M.; Sivakumar, S.M.; Jabeen, A.; Zakir, F.; Islam, F.; Anwer, T.; Bagul, U.S.; Elmobark, M.E.; Khan, G.; Siddiqui, R.; et al. Chapter 8-Nanoparticle System for Anticancer Drug Delivery: Targeting to Overcome Multidrug Resistance. In Multifunctional Systems for Combined Delivery, Biosensing and Diagnostics; Grumezescu, A.M., Ed.; Elsevier: Amsterdam, The Netherlands, 2017; pp. 159-169. [CrossRef]

42. Herda, L.M.; Hristov, D.R.; Lo Giudice, M.C.; Polo, E.; Dawson, K.A. Mapping of Molecular Structure of the Nanoscale Surface in Bionanoparticles. J. Am. Chem. Soc. 2017, 139, 111-114. [CrossRef] [PubMed]

43. Colombo, M.; Fiandra, L.; Alessio, G.; Mazzucchelli, S.; Nebuloni, M.; De Palma, C.; Kantner, K.; Pelaz, B.; Rotem, R.; Corsi, F.; et al. Tumour homing and therapeutic effect of colloidal nanoparticles depend on the number of attached antibodies. Nat. Commun. 2016, 7, 13818. [CrossRef] [PubMed]

44. Faria, M.; Björnmalm, M.; Thurecht, K.J.; Kent, S.J.; Parton, R.G.; Kavallaris, M.; Johnston, A.P.R.; Gooding, J.J.; Corrie, S.R.; Boyd, B.J.; et al. Minimum information reporting in bio-nano experimental literature. Nat. Nanotechnol. 2018, 13, 777-785. [CrossRef] [PubMed]

45. Ma, Z.; Webb, D.J.; Jo, M.; Gonias, S.L. Endogenously produced urokinase-type plasminogen activator is a major determinant of the basal level of activated ERK/MAP kinase and prevents apoptosis in MDA-MB-231 breast cancer cells. J. Cell Sci. 2001, 114, 3387-3396. [PubMed]

46. Ducat, E.; Evrard, B.; Peulen, O.; Piel, G. Cellular uptake of liposomes monitored by confocal microscopy and flow cytometry. J. Drug Deliv. Sci. Technol. 2011, 21, 469-477. [CrossRef]

47. Willis, M.; Forssen, E. Ligand-targeted liposomes. Adv. Drug Deliv. Rev. 1998, 29, $249-271$.

48. Xiao, K.; Li, Y.; Luo, J.; Lee, J.S.; Xiao, W.; Gonik, A.M.; Agarwal, R.G.; Lam, K.S. The effect of surface charge on in vivo biodistribution of PEG-oligocholic acid based micellar nanoparticles. Biomaterials 2011, 32, 3435-3446. [CrossRef] [PubMed]

49. Cochran, B.J.; Gunawardhana, L.P.; Vine, K.L.; Lee, J.A.; Lobov, S.; Ranson, M. The CD-loop of PAI-2 (SERPINB2) is redundant in the targeting, inhibition and clearance of cell surface uPA activity. BMC Biotechnol. 2009, 9, 43. [CrossRef]

50. Conese, M.; Blasi, F. Urokinase/urokinase receptor system: Internalization/degradation of urokinase-serpin complexes: Mechanism and regulation. Biol. Chem. Hoppe-Seyler 1995, 376, 143-155.

51. Ivascu, A.; Kubbies, M. Diversity of cell-mediated adhesions in breast cancer spheroids. Int. J. Oncol. 2007, 31, 1403-1413. [CrossRef]

52. Nichols, J.W.; Bae, Y.H. EPR: Evidence and fallacy. J. Control. Release: Off. J. Control. Release Soc. 2014, 190, 451-464. [CrossRef] 
53. Krasnici, S.; Werner, A.; Eichhorn, M.E.; Schmitt-Sody, M.; Pahernik, S.A.; Sauer, B.; Schulze, B.; Teifel, M.; Michaelis, U.; Naujoks, K.; et al. Effect of the surface charge of liposomes on their uptake by angiogenic tumor vessels. Int. J. Cancer 2003, 105, 561-567. [CrossRef]

54. Gabizon, A.; Isacson, R.; Libson, E.; Kaufman, B.; Uziely, B.; Catane, R.; Ben-Dor, C.G.; Rabello, E.; Cass, Y.; Peretz, T.; et al. Clinical Studies of Liposome-Encapsulated Doxorubicin. Acta Oncol. 1994, 33, 779-786. [CrossRef] [PubMed]

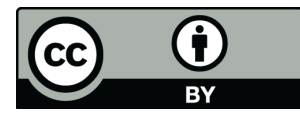

(C) 2020 by the authors. Licensee MDPI, Basel, Switzerland. This article is an open access article distributed under the terms and conditions of the Creative Commons Attribution (CC BY) license (http://creativecommons.org/licenses/by/4.0/). 